\title{
Genome-wide identification, classification and analysis of heat shock transcription factor family in maize
}

\author{
Yong-Xiang Lin ${ }^{\dagger}$, Hai-Yang Jiang ${ }^{\dagger}$, Zhang-Xin Chu, Xiu-Li Tang, Su-Wen Zhu, Bei-Jiu Cheng ${ }^{*}$
}

\begin{abstract}
Background: Heat shock response in eukaryotes is transcriptionally regulated by conserved heat shock transcription factors (Hsfs). Hsf genes are represented by a large multigene family in plants and investigation of the Hsf gene family will serve to elucidate the mechanisms by which plants respond to stress. In recent years, reports of genome-wide structural and evolutionary analysis of the entire Hsf gene family have been generated in two model plant systems, Arabidopsis and rice. Maize, an important cereal crop, has represented a model plant for genetics and evolutionary research. Although some Hsf genes have been characterized in maize, analysis of the entire Hsf gene family were not completed following Maize (B73) Genome Sequencing Project.

Results: A genome-wide analysis was carried out in the present study to identify all Hsfs maize genes. Due to the availability of complete maize genome sequences, 25 nonredundant Hsf genes, named ZmHsfs were identified. Chromosomal location, protein domain and motif organization of $\mathrm{ZmHsfs}$ were analyzed in maize genome. The phylogenetic relationships, gene duplications and expression profiles of $Z \mathrm{mH} / \mathrm{s} f$ genes were also presented in this study. Twenty-five ZmHsfs were classified into three major classes (class A, B, and C) according to their structural characteristics and phylogenetic comparisons, and class A was further subdivided into 10 subclasses. Moreover, phylogenetic analysis indicated that the orthologs from the three species (maize, Arabidopsis and rice) were distributed in all three classes, it also revealed diverse Hsf gene family expression patterns in classes and subclasses. Chromosomal/segmental duplications played a key role in Hsf gene family expansion in maize by investigation of gene duplication events. Furthermore, the transcripts of $25 \mathrm{ZmHsf}$ genes were detected in the leaves by heat shock using quantitative real-time PCR. The result demonstrated that ZmHsf genes exhibit different expression levels in heat stress treatment.

Conclusions: Overall, data obtained from our investigation contributes to a better understanding of the complexity of the maize Hsf gene family and provides the first step towards directing future experimentation designed to perform systematic analysis of the functions of the Hsf gene family.
\end{abstract}

\section{Background}

All organisms possess an evolutionarily conserved, rapid cellular defense mechanism commonly designated as the heat shock (HS) response, which activates a variety of reactions in response to heat stress and a number of chemical stressors. It is characterized by rapid reprogramming of gene expression, leading to the production of a defined set of proteins called heat shock proteins

\footnotetext{
* Correspondence: beijiucheng@ahau.edu.cn

† Contributed equally

Key Lab of Crop Biology, School of Life Sciences, Anhui Agricultural University, Hefei, Anhui, China
}

(Hsps), most of which act as molecular chaperones [1,2]. At the onset of stress, Hsps prevent protein unfolding and aggregation, thereby maintaining cellular protein homeostasis, which determines critical cellular structures and functions to regulate stress response.

Hsps expression is regulated by multiple mechanisms. The central regulators of Hsps expression are heat shock transcription factors. Hsfs are the terminal components of a signal transduction chain mediating the activation of genes responsive to heat or other stress stimuli $[3,4]$. Under normal growth conditions, Hsf is maintained in an inert monomer state through

\section{Biomed Central}


association with molecular chaperones such as Hsp70. In response to heat shock, Hsf is converted from a transcriptional inactive monomer to active trimmer using oligomerization domains, which function as sequencespecific trimeric DNA binding proteins. Hsfs are capable of recognizing the conserved binding motifs (heat shock elements, HSEs) within the promoters of Hsf-responsive genes [5]. The consensus HSEs contain a cis-acting sequence, which consists of multiple inverted repeats of the 5'-nGAAn-3' sequence (where $\mathrm{n}$ is any nucleotide) [6]. At least three 5'-nGAAn-3' repeats are required for a functional HSE, and additional reiteration of the pentameric unit results in higher affinity interactions between Hsf and HSE [7].

Plant Hsfs genes have been isolated from various species [8-11]. Similar to many other transcription factors, the Hsf family has a modular structure. Despite considerable variability in size and sequence, Hsfs are structurally and functionally conserved throughout the eukaryotic kingdom. Several highly conserved domains exist in the modular structure and all characterized Hsfs have a common core structure comprised of DNA binding and oligomerization domains [4,12]. In addition, another well-defined domain is a nuclear localization signal domain (NLS). Apart from this, a C-terminal activation domain (CTAD) and a nuclear export signal (NES) are included in some Hsfs $[4,13]$.

Close to the N-terminal, the highly structured DNAbinding domain (DBD) is the most conserved component of Hsfs, consisting of an antiparallel four-stranded $\beta$-sheet $(\beta 1-\beta 2-\beta 3-\beta 4)$ packed against a bundle of three $\alpha$-helices (H1, H2, H3). The hydrophobic core of this domain forms a helix-turn-helix (H2-T-H3) structure required for specific recognition of the HSE conserved motif [14]. An adjacent oligomerization domain (HR$\mathrm{A} / \mathrm{B}$ region) composed of hydrophobic heptad repeats is separated from the DBD domain by a flexible linker. Through hydrophobic interactions, the heptad repeats form a helical coiled-coil structure reported responsible for the trimerization of Hsfs [15]. Plant Hsf protein families fall into three classes (A, B, and C) by peculiarities of their HR-A/B regions [4]. All class $\mathrm{A}$ and class $\mathrm{C}$ Hsfs have an extended $\mathrm{HR}-\mathrm{A} / \mathrm{B}$ region due to an insertion of 21 (class A) or seven (class $C$ ) amino acid residues between the $\mathrm{A}$ and $\mathrm{B}$ of the $\mathrm{HR}-\mathrm{A} / \mathrm{B}$ region. In contrast, class B Hsfs are discriminated from class $A$ and $C$ by the absence of this insertion and the presence of a single, continuous heptad repeat pattern. Furthermore, the variable length of the linker between DBD domain and HR-A/B region also offer additional support for this classification (nine to 39 amino acid residues for class $\mathrm{A}, 50$ to 78 amino acid residues for class $\mathrm{B}$ and 14 to 49 amino acid residues for class $\mathrm{C}$ Hsfs) [4].
Furthermore, at the C-terminus from the HR-A/B region a cluster of basic amino acids rich in arginine and lysine residues serve as a nuclear localization signal (NLS), which is required for nuclear import [16]. The NES is positioned at the C-terminus of some plant Hsfs. The overall balance of nuclear import and export processes directed by the strength and accessibility of the NLS and NES determines intracellular distribution of plant class A Hsfs [13,17]. Sequence comparison studies and functional analyses indicate that the combination of C-terminal activator motifs (AHA motifs) adjacent to a nuclear export signal (NES) represents the core of the C-terminal activation domain (CTAD) for many plant class A Hsfs [13,18]. AHA motifs are rich in aromatic (W, Y, F), hydrophobic (L, I, V) and acidic amino acid residues $(\mathrm{D}, \mathrm{E})$. On the other hand, class $\mathrm{B}$ and $\mathrm{C}$ Hsfs have no activator function of their own resulting from the lack of AHA motifs [13].

The Hsf gene family has been thoroughly characterized in Arabidopsis and rice [4,19], whose genomes have been sequenced. Furthermore, Hsfs have been comprehensively studied in tomato $[8,17,18]$. Previous study has reported several Hsf genes cloned from maize [20]. The Maize Genome Sequence Project completed full maize genome assembly (Zea mays L. B73) [21]. This provides an opportunity to deduce the maize Hsf gene family and infer its evolutionary history and adaptations in heat and chemical stress response mechanisms at the molecular level. In the present study, we searched for all nonredundant sets of ZmHsf genes and predicted their presumed structures. The results of this work provide a foundation to better understand functional and evolutionary history of the Hsf gene family in angiosperms.

\section{Results}

\section{Identification and physical locations of Hsf proteins in} maize

The amino acid sequence of Hsf-type DBD domain (Pfam: PF00447) was adopted as a query in BLASTP searches for possible homologs encoded in the maize genome. As a result, 48 candidate $\mathrm{Hsf}$ protein sequences were identified in maize. Subsequently, all candidate Hsf protein sequences were surveyed to further verify whether they contain Hsf-type DBD domains using the Pfam database. Twenty-one candidate Hsf protein sequences were discarded for incomplete the Hsf-type DBD domain and overlapping genes. Furthermore, two sequences were removed due to the absence of a coiled-coil structure by the SMART program. Consequently, 25 nonredundant maize Hsfs were identified and described (Table 1). All nonredundant maize Hsfs were mapped on the 10 maize chromosomes (Figure 1). Hsfs were distributed in every 
Table $1 \mathrm{ZmHsf}$ protein information

\begin{tabular}{|c|c|c|c|c|c|c|}
\hline Number & Gene name & Translation & Size(aa) & MW (Da) & $\mathrm{pl}$ & Chromosome \\
\hline 1 & ZmHsf-01 & GRMZM2G165972_P02 & 384 & 43268.46 & 5.30 & 1 \\
\hline 2 & ZmHsf-02 & GRMZM2G118485_P02 & 417 & 46816.21 & 5.09 & 1 \\
\hline 3 & ZmHsf-03 & GRMZM2G164909_P01 & 414 & 44382.81 & 6.80 & 1 \\
\hline 4 & ZmHsf-04 & GRMZM2G010871_P01 & 357 & 40502.49 & 4.99 & 1 \\
\hline 5 & ZmHsf-05 & GRMZM2G132971_P01 & 359 & 40587.23 & 5.57 & 1 \\
\hline 6 & ZmHsf-06 & GRMZM2G115456_P01 & 527 & 56724.50 & 5.11 & 1 \\
\hline 7 & ZmHsf-07 & GRMZM2G088242_P01 & 394 & 41742.83 & 7.81 & 2 \\
\hline 8 & ZmHsf-08 & GRMZM2G002131_P01 & 298 & 32270.31 & 9.13 & 2 \\
\hline 9 & ZmHsf-09 & GRMZM2G089525_P01 & 331 & 35883.69 & 5.94 & 3 \\
\hline 10 & ZmHsf-10 & GRMZM2G005815_P01 & 462 & 50970.67 & 8.87 & 3 \\
\hline 11 & ZmHsf-11 & GRMZM2G098696_P01 & 370 & 39562.03 & 5.89 & 4 \\
\hline 12 & ZmHsf-12 & GRMZM2G384339_P01 & 497 & 54104.58 & 5.06 & 5 \\
\hline 13 & ZmHsf-13 & GRMZM2G105348_P01 & 257 & 27836.98 & 5.85 & 5 \\
\hline 14 & ZmHsf-14 & GRMZM2G179802_P02 & 528 & 58138.65 & 5.57 & 5 \\
\hline 15 & ZmHsf-15 & GRMZM2G059851_P01 & 508 & 56061.66 & 4.96 & 5 \\
\hline 16 & ZmHsf-16 & AC206165.3_FGP007 & 469 & 51623.79 & 5.41 & 6 \\
\hline 17 & ZmHsf-17 & GRMZM2G125969_P01 & 375 & 42043.73 & 4.70 & 7 \\
\hline 18 & ZmHsf-18 & GRMZM2G139535_P01 & 298 & 32258.35 & 9.53 & 7 \\
\hline 19 & ZmHsf-19 & GRMZM2G165272_P01 & 394 & 41468.10 & 5.00 & 7 \\
\hline 20 & ZmHsf-20 & AC205471.4_FGP003 & 446 & 49718.46 & 5.15 & 8 \\
\hline 21 & ZmHsf-21 & GRMZM2G086880_P01 & 348 & 37409.50 & 8.09 & 8 \\
\hline 22 & ZmHsf-22 & GRMZM2G118453_P01 & 433 & 48647.71 & 5.25 & 8 \\
\hline 23 & ZmHsf-23 & GRMZM2G173090_P02 & 350 & 38154.66 & 4.95 & 9 \\
\hline 24 & ZmHsf-24 & GRMZM2G026742_P01 & 407 & 45317.63 & 4.97 & 9 \\
\hline 25 & ZmHsf-25 & GRMZM2G301485_P01 & 318 & 33947.51 & 5.70 & 10 \\
\hline
\end{tabular}

Heat shock transcription factors identified from maize are listed with their names according to their chromosome location in Figure 1. Proteins are designated according to their Sequenced ID, the protein sequence length, molecular weight (MW), isoelectric point (pl) and chromosomal locations.

chromosome of the maize genome, however, the number of Hsf genes on each chromosome varied widely. The largest number, comprised of six Hsf genes, was detected on chromosome 1, whereas the least number was found on chromosomes 4, 6 and 10, including only one Hsf gene.

\section{Conserved Domains and Motifs in maize Hsf proteins}

The modular structure of heat shock transcription factor was studied thoroughly in some model plants $[4,8]$. The detailed knowledge regarding tomato and Arabidopsis Hsfs functional domains enabled us to analyze similar domains for the $25 \mathrm{Hsfs}$ identified from the maize genome

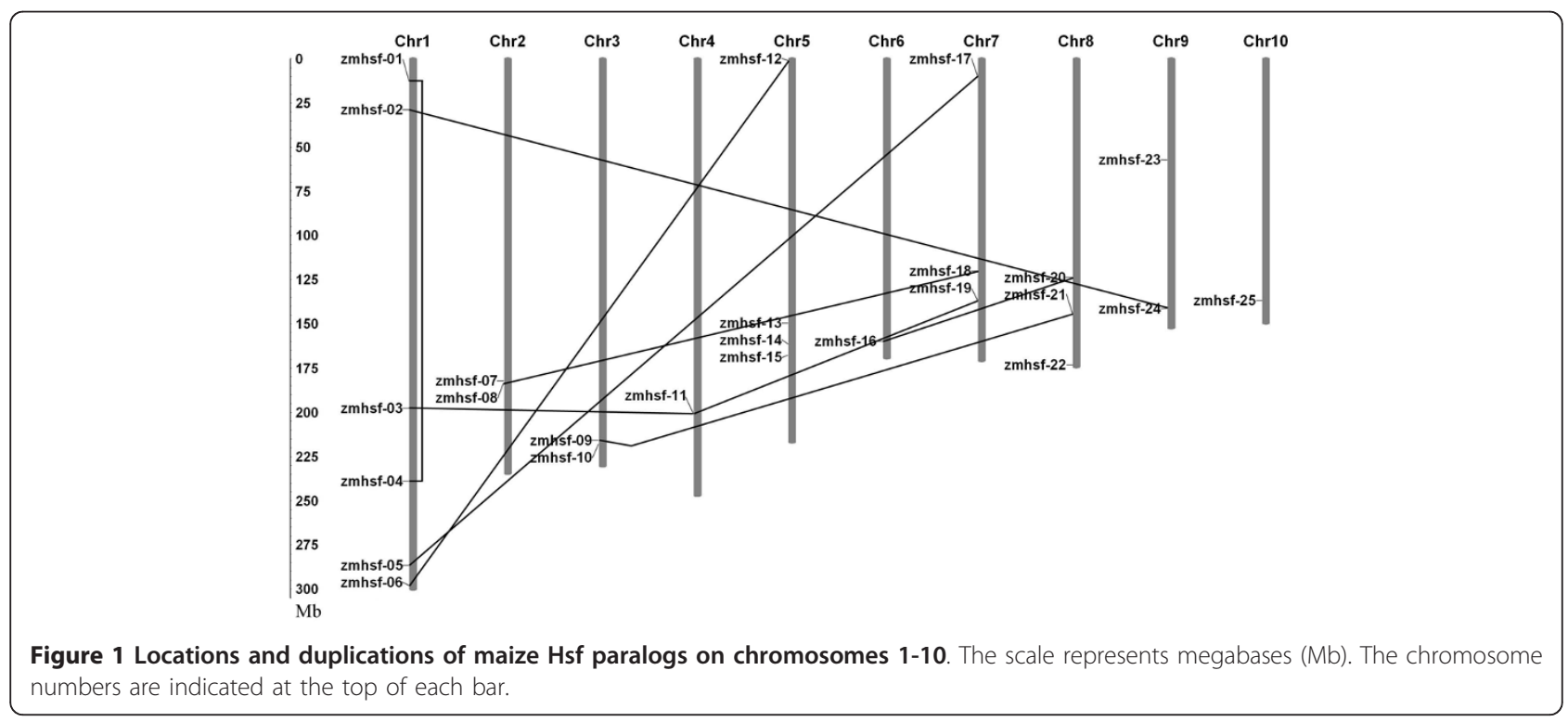


Table 2 Functional domains and motifs of maize Hsfs

\begin{tabular}{|c|c|c|c|c|c|c|}
\hline Gene name & Group & DBD & OD & NLS & NES & AHA motifs \\
\hline ZmHsf-01 & $\mathrm{A} 2$ & $41-134$ & $167-217$ & (247) RKRRR & (296) LENLALNI & AHA (336) DDFWEELLNE \\
\hline ZmHsf-02 & A9 & $48-140$ & $180-230$ & (254) NRKRR & & \\
\hline \multirow[t]{2}{*}{ ZmHsf-04 } & $A 2$ & $43-136$ & $168-218$ & (233) KRK7KKKRRR & (344) LAQQLGYL & AHA1 (267) LKMFESGVLN \\
\hline & & & & & & AHA2 (314) DDFWAELLVE \\
\hline ZmHsf-05 & $\mathrm{A} 2$ & $37-130$ & 159-209 & (224) MRK7KKRRRR & & AHA (314) DDFWEDLLHE \\
\hline ZmHsf-06 & $\mathrm{A} 1$ & $56-149$ & $186-236$ & (261) KKRR & (505) IGDLTEQM & AHA (470) DSFWEQFL \\
\hline $\mathrm{ZmHsf-10}$ & A6 & $137-232$ & $263-313$ & (337) KRQR & & AHA (401) SDWWDELDLD \\
\hline $\mathrm{ZmHsf-12}$ & A1 & $29-122$ & $159-209$ & (234) KKRR & (477) LTEQM & AHA (436) NSIWEQFL \\
\hline $\mathrm{ZmHsf-14}$ & A5 & $66-160$ & $187-237$ & (261) HKKRR & (387) LNLSL & AHA (479) DKFWEQFLTE \\
\hline \multirow[t]{2}{*}{ ZmHsf-15 } & A3 & $73-166$ & 193-243 & (267) KRKFLK & (405) LSPLPDNMG & AHA1 (432) EQIWGVDASA \\
\hline & & & & & & AHA2 (472) ERFWELDFQA \\
\hline $\mathrm{ZmHsf-16}$ & A4 & $22-115$ & $145-195$ & (215) SKKRR & & AHA (408) DVFWERFLTD \\
\hline ZmHsf-17 & $\mathrm{A} 2$ & $49-142$ & $172-222$ & (237) MRK7KKRRRR & (359) LSEKMGYL & AHA (332) DNFWEQLLNE \\
\hline ZmHsf-20 & A4 & $10-103$ & 133-183 & (203) SKKRR & & AHA (387) DVFWERFLTD \\
\hline ZmHsf-22 & A4 & $7-100$ & $130-180$ & (197) GKKRR & (155) MQELEDKLIF & AHA (368) DGFWQQFLTE \\
\hline \multirow[t]{2}{*}{ ZmHsf-23 } & A6 & $48-141$ & $167-217$ & (239) RKRR & (257) LDIEELAM & AHA1 (291) DMIWYELLGE \\
\hline & & & & & & AHA2 (324) AQPWAEMDE \\
\hline ZmHsf-24 & A9 & $48-141$ & $180-230$ & (254) NRKRR & & \\
\hline ZmHsf-03 & B & $69-162$ & $231-260$ & (337) RKRMR & & \\
\hline ZmHsf-07 & B & $19-113$ & $226-255$ & (276) RKK & (369) LALECAGLSL & \\
\hline ZmHsf-08 & B & $15-108$ & $175-203$ & (259) RKRAR & (206) VRQLDLGL & \\
\hline $\mathrm{ZmHsf-11}$ & B & $34-127$ & $199-228$ & (297) RKRMR & & \\
\hline $\mathrm{ZmHsf-18}$ & B & $17-110$ & $172-201$ & (259) RKRGR & (203) VRQLDLRL & \\
\hline ZmHsf-19 & B & $42-135$ & $217-246$ & (318) KRMR & & \\
\hline ZmHsf-25 & B & 8-101 & $161-190$ & (232) KRLR & (279) LDVLTLSV & \\
\hline ZmHsf-09 & C & $24-117$ & $171-207$ & (224) KKRRR & & \\
\hline $\mathrm{ZmHsf-13}$ & C & $12-104$ & 135-171 & (202) KRAR & & \\
\hline $\mathrm{ZmHsf-21}$ & C & $32-125$ & $176-212$ & (229) KKRRR & & \\
\hline
\end{tabular}

Numbers in brackets indicate position of the putative nuclear localization signal (NLS), nuclear export signal (NES), and activator (AHA) motifs in the C-terminal domain. Putative NLS can be monopartite (e.g., ZmHsf-01, ZmHsf-09) or bipartite (e.g., ZmHsf-04, ZmHsf-05).

(Table 2). Five conserved domains were observed in the majority of the maize Hsf proteins. The multiple alignment clearly showed the highly structured DBD domain of approximately 100 amino acids, located in the proteins amino-terminal section, which was the most conserved section of maize Hsfs (Figure 2). MARCOIL was used to predict the coiled-coil structure characteristic of Leu-zipper type protein interaction domains, which is a property of the HR-A/B region in the Hsf protein sequences. The putative HR-A/B regions were consistently characterized by the predicted coiled-coil structure (Figure 3). Information regarding the potential NLS and NES domains in maize Hsf protein sequences, which are crucial for dynamic intracellular distribution of Hsfs between the nucleus and cytoplasm, were obtained by PredictNLS and NetNES. Nearly all Hsfs contain two clusters of basic amino acid residues (K/R motifs), which might serve as potential NLS motifs. Results obtained from mutation analysis of the two potential NLS motifs from two related tomato Hsfs (HsfA1 and HsfA2) indicated that only one of the two motifs adjacent to the HR-A/B region, and not the conserved $\mathrm{C}$-terminal part of the DBD domain is functional as an Hsf protein nuclear localization signal $[16,17,22]$. Prediction programs, sequence comparisons and cognitive models generated from previous research detected a wide range of putative NLSs, which were monopartite or bipartite clusters and found close to the Cterminal of the HR-A/B region of maize Hsfs. Similarly, some putative NESs were identified close to the C-terminal of maize Hsfs. However, the following exceptions were observed: ZmHsf-08, ZmHsf-18 and ZmHsf-22. ZmHsf-08 and ZmHsf-18 NESs were closer to the HR-A/ $B$ regions than to NLSs. In particular, ZmHsf-22 NES was located in the HR-A/B domain region. As described by Nover et al (2001) and based on preceding investigations with the AHA motifs of tomato Hsf A1 and A2, we used sequence comparisons and predicted the putative AHA motifs in the center of the C-terminal activation domains for most class A maize Hsfs (Table 2). However, we were unable to predict class B and C putative AHA motifs. 


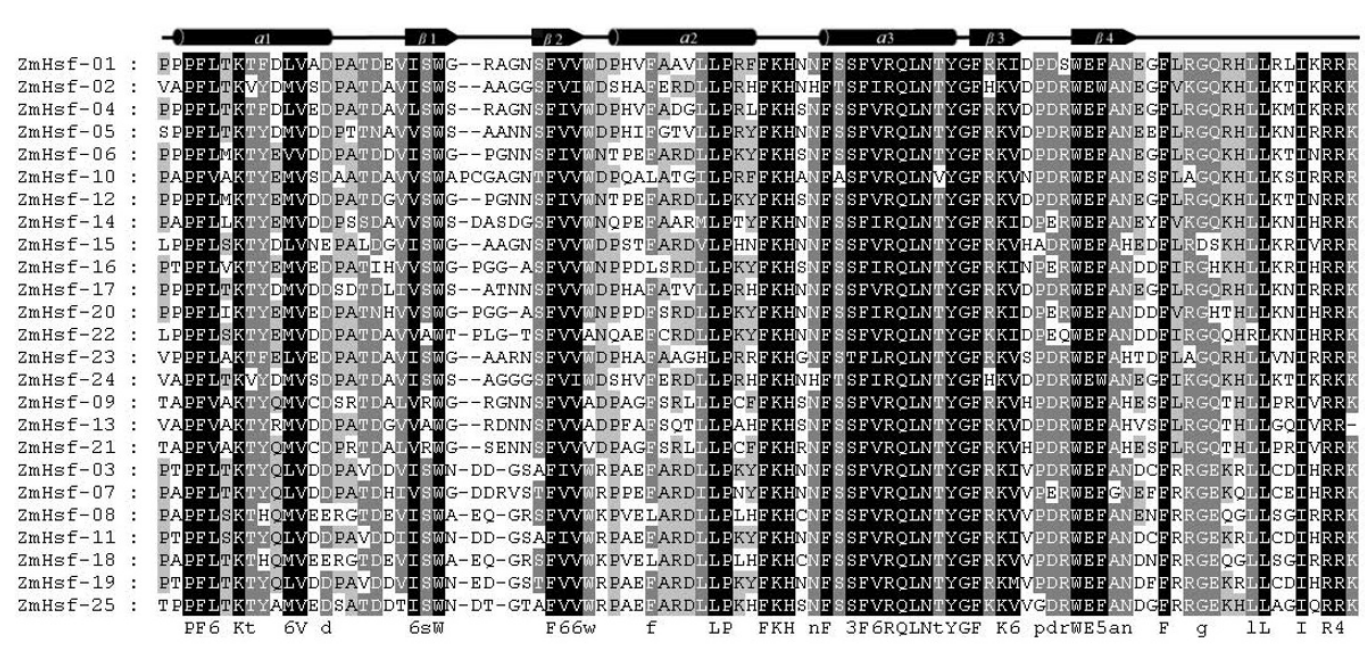

Figure 2 Multiple sequence alignment of the DBD domains of the Hsf protein family in maize. The definition of the Hsf numbers corresponds to the order of alignment. The multiple alignment results clearly show the highly conserved DBD domains among maize Hsf genes. The secondary structure elements of $\operatorname{DBD}(\alpha 1-\beta 1-\beta 2-\alpha 2-\alpha 3-\beta 3-\beta 4)$ are shown above the alignment. Cylindrical tubes represent $\alpha$-helices and block arrows represent $\beta$-sheets.

MEME web server was employed as a secondary method to analyze motif distribution and verify the results of domain prediction (Figure 4; Table 3). Specifying the DBD domain, motif 1 was found in 25 members of the maize Hsf family. Specifying the coiled-coil structure, motifs 2 and 6 were distinctively detected in all members of maize Hsf family. All class B proteins exhibited the motif 6-type coiled-coil region, whereas motif 2-type coiled-coil region was only detected in classes $A$ and $C$. The conserved motifs 10 and 15 were identified as NLS, which were widely distributed in the

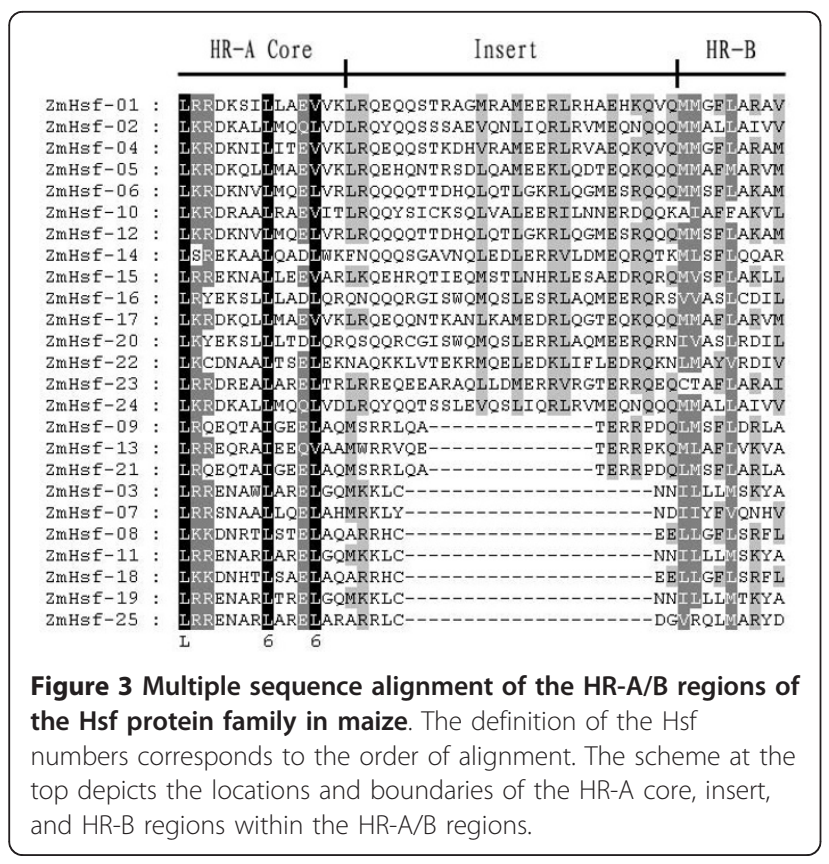

maize Hsf family. Motif 10 was characteristic of class A and class $C$, and the NLS domain was represented by motif 15 in class B. Furthermore, motifs 13 and 9 represented NES and AHA motifs, respectively, which were detected close to the Hsfs C-terminal. Lastly, some unknown motifs were also identified by MEME motif analysis.

Overall, despite variability in size and sequence, the predicted Hsf DBD, HR-A/B region and NLS domain were observed in each maize Hsfs by two combined methods. Although MEME motifs did not correspond precisely to individual putative NES and AHA domains defined by domain prediction of the first method, it was clearly indicated that a fraction of maize Hsfs contained NES domains and the majority of class A maize Hsfs had putative AHA domains.

\section{Phylogenetic and evolutionary analysis in maize Hsf proteins}

In order to analyze the phylogenetic organization of the Hsf families, a phylogenetic analysis of 25 maize Hsfs, 25 rice Hsfs (OsHsfs) and 21 Arabidopsis Hsfs (AtHsfs) was performed by generating a phylogenetic tree (Figure 5). The OsHsf and AtHsf protein sequences were downloaded from the rice genome annotation (TIGR) [23] and the Arabidopsis Information Resources (TAIR) [24]. All Hsfs fell broadly into three major classes: classes A, B and $C$, with well-supported bootstrap values, which included representative genes of maize, rice and Arabidopsis besides AtHsf-08 (HsfC1). In this study, class A was further subdivided into ten subclasses according to their bootstrap values and phylogenetic relationship, designated as A1, A2, A3, A4, A5, A6, A7, A8, A9 and 


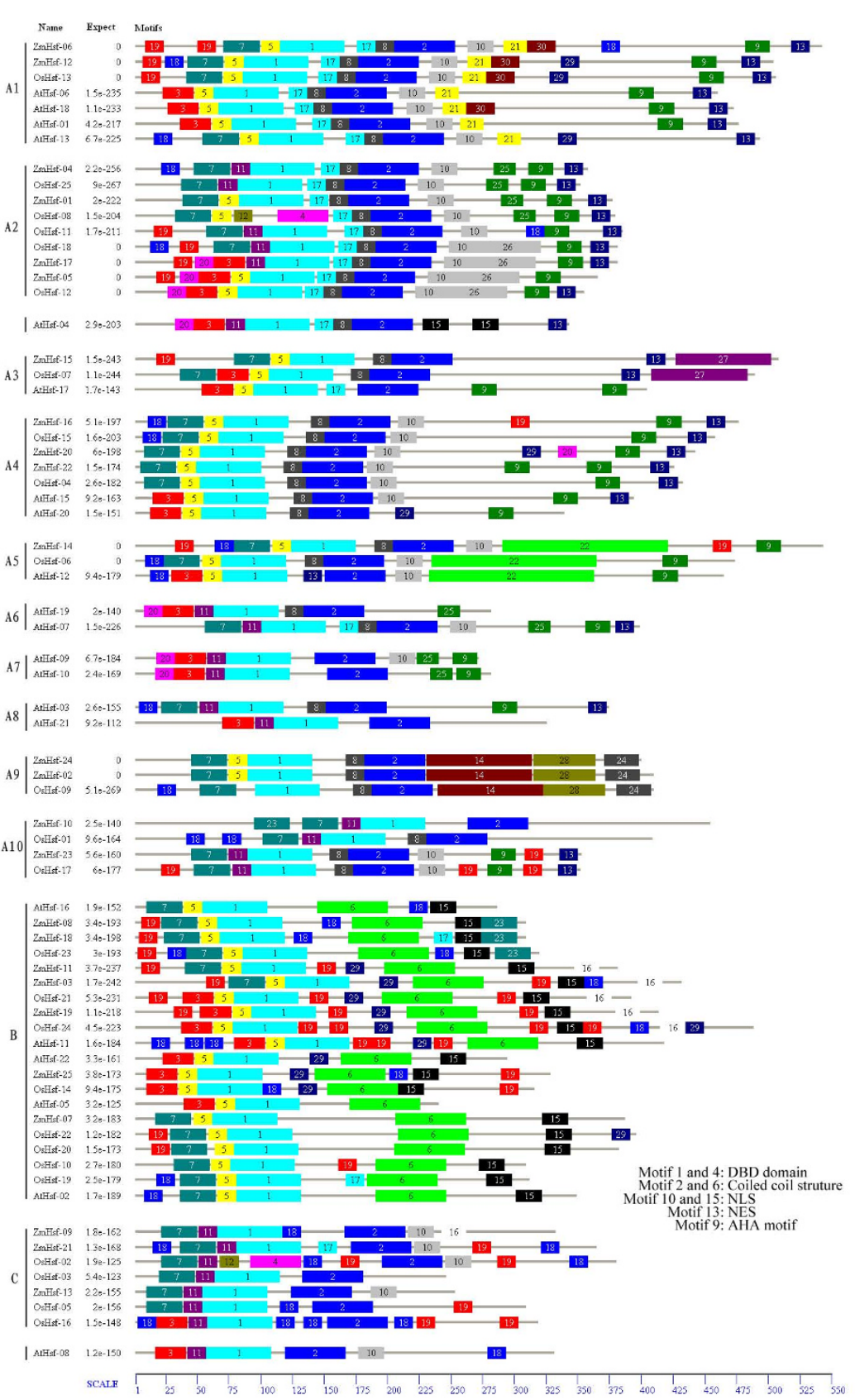

Figure 4 Distribution of conserved motifs in the Hsf family members. All motifs were identified by MEME using the complete amino acid sequences of 71 maize, rice and Arabidopsis Hsf genes documented in Figure 5. Names of all members among the defined gene clusters and combined $P$-values are shown on the left side of the figure and motif sizes are indicated the bottom of the figure. Different motifs are indicated by different colors numbered 1-30. The same number in different proteins refers to the same motif with the exception of motif 15 in AtHsf-04. Because AtHsf-04 exhibits two boxes of motif 15, the box near the N-terminal represents NLS and the box close to the C-terminal specifies AHA. For details of motifs refer to Table 3 .

A10. In our analysis, AtHsf-21 (A9 by annotation) did not cluster with subclass A9 but was grouped into subclass A8. In addition, AtHsf-04 (A2 by annotation) and AtHsf-08 (C1 by annotation) were not classed in the Hsf subclass A2 and class $\mathrm{C}$ respectively. Moreover, ZmHsf-
10, ZmHsf-23, OsHsf-01 and OsHsf-17 constituted subclass A10 clade. The motif distribution analyzed by MEME was also indicated in Figure 4, which was basically consistent with the phylogenetic analysis. The members of the same subclass usually share several class- and 
Table 3 Motif sequences identified by MEME tools

\begin{tabular}{|c|c|}
\hline Motif & Multilevel consensus sequence \\
\hline 1 & PKYFKHNNFSSFVRQLNTYGFRKIDPDRWEFANECFLRGQKHLLKNIHRRKP \\
\hline 2 & NVLMQEWKLRQQQQTTKWQMQAMEQRLQHMEQRQQQMMSFLAKVMQNP \\
\hline 3 & PFLTKTYDMVDDPATDHVISWNEDN \\
\hline 4 & SFVRQLNTYGFRKVDPDRWEFANECFLRGQKHLLCNIHRRK \\
\hline 5 & SFWWNPHEFARDLL \\
\hline 6 & AGSCPAYADLMEENERLRRENARLTRELAHMKKLCNNIIYFMSNYVDPQQPDAAKAM \\
\hline 7 & SGPAPFLTKTYQMVCDPATDHVISWGPCG \\
\hline 8 & YFGYEEEIERLKRDK \\
\hline 9 & AEINDDFWEQFLTEGPGCCE \\
\hline 10 & EMRKELIDAISKKRRRPIDDC \\
\hline 11 & SFWWDPHAFSQTLL \\
\hline 12 & YFKHNNFS \\
\hline 13 & DNMDVLTEQMGYLSS \\
\hline 14 & $\begin{array}{l}\text { FLNQLVQQQRRSNWWNDDGNRKRRFQALEHGPVDDQETSGGGAQ\|QYCPPVPETSNQPIPANEA } \\
\text { FCSTPAQPVSSPALEMPMDV }\end{array}$ \\
\hline 15 & DEDKCVKLFGVSIGDKRMRDH \\
\hline 16 & QPWPIYRPRPVYHPIRPCNG \\
\hline 17 & PQYQQQSVGSCVEVG \\
\hline 18 & GGGGGGGG \\
\hline 19 & AAAAAA \\
\hline 20 & PMEGLHEVGPP \\
\hline 21 & ASLDGQIVKYQPMINEAAK \\
\hline 22 & $\begin{array}{l}\text { TSFYDDHSSTSKQEMGNLLNQHFSDKLKLGLCPAMTESNIITLSTQSSHEDNGSPHGKHPDCDMMGME } \\
\text { CLPLVPQMMELSDTGTSICPSKSVCFTPPINDDGFLPCHLNLTLASCPMDVDKSQIPDANGNTID }\end{array}$ \\
\hline 23 & RCEEAAASERPIKMIRIGEPWIGVPSSGP \\
\hline 24 & YDHPWLEQDCQMEAQQNCKNPQYADVIT \\
\hline 25 & ELENLALNIQGLGKGKID \\
\hline 26 & PEADDMGTGSSLEQGSPVLFEPQDPVEFLIDGIPSDLESSAVDAHGLIAPQDI \\
\hline 27 & MDADDDERIWGVDASAALQSSCSGTSQQAYGSHVSDPYLMDIANKPEKFWELDFQALDDGDLQLDKCVIDDPALQQQ \\
\hline 28 & MASNNVGTFDSTGNDFTDTSALCEWDDMDIFGGELEHILQQPEQDFQVDP \\
\hline 29 & SPTYSGEEQVISSNS \\
\hline 30 & AMLRKILKLDSSHRFESMGNSDN \\
\hline
\end{tabular}

Numbers correspond to the motifs described in Figure 4.

group-specific conserved motifs in addition to the Hsf DBD, HR-A/B region, and NLS domain. Putative orthologous proteins were also identified in the tree, including, for example, ZmHsf-17 and OsHsf-18, ZmHsf-07 and OsHsf-22.

\section{Hsf gene duplications in the maize genome}

The potential mechanisms involved in the evolution of the maize Hsf gene family were elucidated by analyzing the duplication events that may have occurred during maize genome evolution. Nine total duplicated gene pairs of the 25 maize heat shock factors were identified, including eight segmental duplication events between chromosomes (e.g. ZmHsf-08 and ZmHsf-18, ZmHsf-09 and $Z m H s f-21)$ as well as one duplication event within the same chromosome ( $Z m H s f-01$ and $Z m H s f-04)$ linked with lines (Figure 1). ZmHsf-11 participated in two duplication events with ZmHsf-03 and ZmHsf-19 and each of these three genes belonged to class B. Chromosome 10 was not involved in any duplication events.

\section{Digital expression analysis: EST expression profile}

Maize Hsfs expression patterns were studied using corresponding EST database with known $Z m H s f s$ coding sequence, resulted in the assignment of $Z m H s f s$ to ten groups on the basis of tissue and organ types (Table 4). In addition, other expression evidence was verified in MAGI and PlantGDB databases (Table 4). After integrating and analyzing all expression data, we found all $Z m H s f s$ were supported by expression evidence with the exception of the ZmHsf-16 gene. Interestingly, ZmHsf03, ZmHsf-11, ZmHsf-15, and ZmHsf-19 were found for expression in seeds, ZmHsf-07 in shoot tips, and ZmHsf17 in roots. Furthermore, $Z m H s f$ duplicated gene pair expression patterns were investigated, only two pairs (ZmHsf-03 and ZmHsf-11, ZmHsf-11 and ZmHsf-19) of 


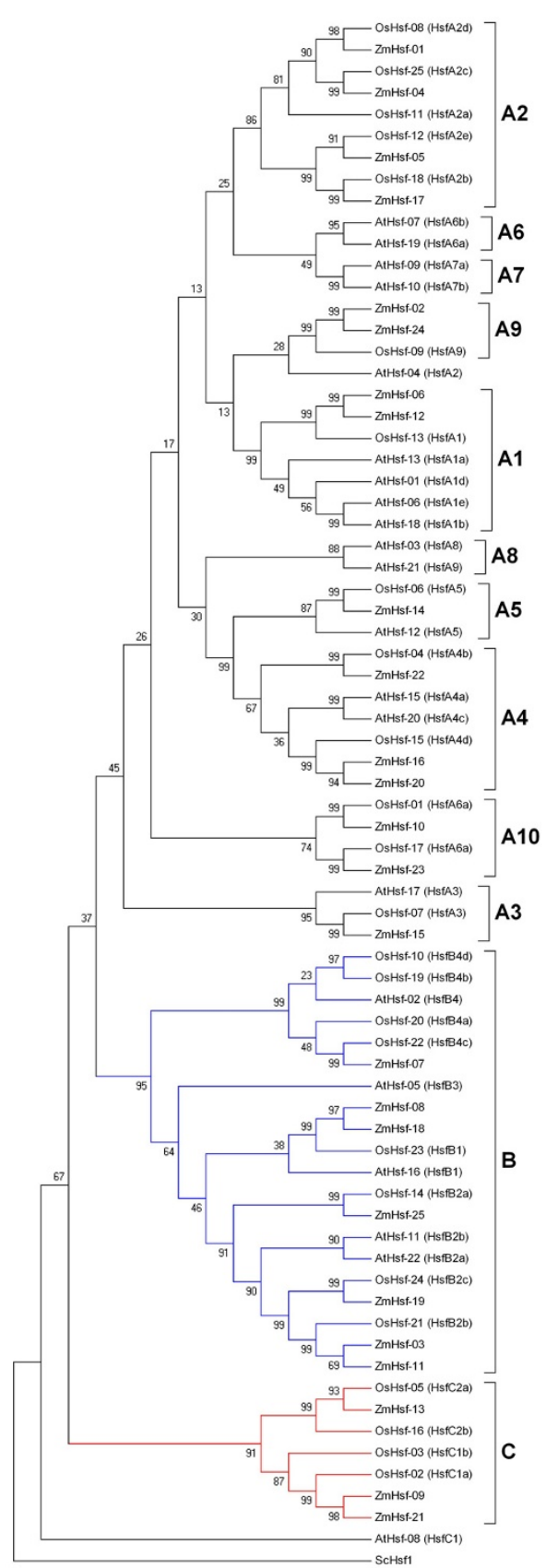

Figure 5 Neighbor-joining phylogenetic tree of the Hsf members. The phylogenetic tree, constructed with MEGA4.0, has been generated on the basis of the amino acid sequences of the $\mathrm{N}$ terminal domains of Hsfs including the DNA-binding domain, the $\mathrm{HR}-\mathrm{A} / \mathrm{B}$ region and parts of the linker between both two regions. ScHsf1 was set as the outgroup. Hsf proteins are divided into twelve groups (A1, A2, A3, A4, A5, A6, A7, A8, A9, A10, B, C) based on previous research [4] and high bootstrap values ( $>50)$. The contents in brackets are corresponding Hsf annotations. Branches of members belonging to class A subclasses are represented by black lines, branches of members belonging to class $B$ are represented with blue lines, and branches of members belonging to class $C$ are represented with red lines. The abbreviations of species names are as follows: Zm, Zea mays; Os, Oryza; At, Arabidopsis thaliana. nine shared the same expression patterns between the two members of each gene pair. In the other seven duplicated gene pairs, two paralogs of each gene pair exhibited dissimilar expression patterns. $\mathrm{ZmHsf-04}$ was detected in husks and seeds, however, its paralogue gene ZmHsf-01 appeared to have no tissue-specific expression pattern.

\section{Expression analysis of $\mathrm{ZmHsf}$ gene family under heat stress treatment}

To examine if these predicted genes were expressed in maize and to further confirm their stress-responsiveness to abiotic stress, quantitative real-time PCR was performed for $25 \mathrm{ZmHsf}$ genes in the leaves of maize exposed to heat stress. The analysis revealed that these genes are differentially expressed in the leaves under heat stress condition (Figure 6). Twenty-two genes showed expression activity in maize leaves by heat stress. Most of these responsive genes showed up-regulation of their expression, in which 12 genes were significantly up-regulated ( $>2$-fold). Interestingly, six members including ZmHsf-01, ZmHsf-03, ZmHsf-04, ZmHsf-23, ZmHsf-24 and ZmHsf-25 showed no expression or only faint expression in the leaves of maize under normal growth conditions, however, they were strongly up-regulated during heat stress treatment. Five genes (ZmHsf-06, ZmHsf-10, ZmHsf-14, ZmHsf-20 and $Z m H s f-21)$ were greatly down-regulated $(<0.5$-fold) during the heat stress treatment. Three genes ( $\mathrm{ZmHsf-07,ZmHsf-}$ 09, and ZmHsf-18) of 25 genes exhibited no expression in the leaves of normal and treated plants. Moreover, our results showed that the transcript levels of five $Z m H s f s$ (ZmHsf-05, ZmHsf-08, ZmHsf-12, ZmHsf-13 and ZmHsf16) did not present many changes in heat stress treatment. By comparing the expression data of each pair of duplicated $\mathrm{ZmHsf}$ genes, nine pairs of duplicated genes exhibited significant divergence in their expression levels following heat stress treatment. For example, ZmHsf-06 was dramatically down-regulated, while $\mathrm{ZmHsf-12}$ showed slight increase in transcripts at heat stress treatment.

\section{Discussion}

In this study, a comprehensive set of 25 nonredundant heat shock factors were identified and characterized from the current version of the maize (B73) genome. In a former publication, 22 maize Hsf isoforms were reported, which were composed of 16 Hsfs having intact ORFs and six 5' truncated Hsfs [25]. The following are likely responsible for these discrepancies. In the previous studies, the maize genome had not been completely sequenced, 22 maize Hsf genes were identified by searching the publicly available maize EST and genomic sequence survey (GSS) databases for homology to rice Hsfs. In our study, the maize genome has been 
Table 4 Digital expression analysis of $\mathrm{ZmHsf}$ genes

\begin{tabular}{|c|c|c|c|c|c|c|c|c|c|c|c|c|c|c|c|}
\hline \multirow[t]{2}{*}{ Gene } & \multicolumn{10}{|c|}{ Tissue and organ type (NCBI) } & \multirow{2}{*}{$\begin{array}{l}\text { Number of } \\
\text { ESTs in dbEST }\end{array}$} & \multirow[t]{2}{*}{ MAGI } & \multicolumn{3}{|c|}{ PlantGDB } \\
\hline & Silks & Husks & Shoot tips & Leaf & Root & Seedling & Tassel & Ear & Seed & Multiple & & & EST & cDNA & PUTs \\
\hline ZmHsf-01 & & & & & & & & & & + & 9 & + & + & & + \\
\hline ZmHsf-02 & + & & + & + & & + & & & + & + & 7 & + & + & & \\
\hline ZmHsf-03 & & & & & & & & & + & & 1 & & + & & \\
\hline ZmHsf-04 & & + & & & & & & & + & + & 14 & + & + & + & + \\
\hline ZmHsf-05 & & & & + & + & & & + & + & + & 20 & + & + & + & + \\
\hline ZmHsf-06 & + & + & & + & + & + & & & + & + & 17 & + & + & + & + \\
\hline ZmHsf-07 & & & + & & & & & & & + & 3 & & & & \\
\hline ZmHsf-08 & & & & & + & & & & + & + & 27 & & + & & \\
\hline ZmHsf-09 & & & & & & & & & & + & 5 & & & & \\
\hline ZmHsf-10 & & & & & & & & & & + & 6 & & + & & \\
\hline ZmHsf-11 & & & & & & & & & + & + & 9 & & + & & \\
\hline ZmHsf-12 & & & & + & & & + & + & + & + & 11 & + & + & + & \\
\hline ZmHsf-13 & & & & & + & & & & + & + & 11 & + & + & & \\
\hline ZmHsf-14 & + & + & & + & + & & + & & + & + & 23 & & & & \\
\hline ZmHsf-15 & & & & & & & & & + & + & 6 & + & + & & \\
\hline ZmHsf-16 & & & & & & & & & & & 0 & & & & \\
\hline ZmHsf-17 & & & & & + & & & & & + & 11 & + & + & & \\
\hline ZmHsf-18 & & & & & & & & & & & 0 & & + & & \\
\hline ZmHsf-19 & & & & & & & & & + & + & 5 & & + & & + \\
\hline ZmHsf-20 & & & + & & & & & + & & + & 4 & & & & \\
\hline ZmHsf-21 & & & + & + & & & & & + & & 1 & & & & \\
\hline ZmHsf-22 & & & & & & & & & & + & 11 & + & + & + & + \\
\hline ZmHsf-23 & & & & & & & & & & + & 2 & & & & \\
\hline ZmHsf-24 & & & & & & & & & & + & 8 & + & + & + & + \\
\hline ZmHsf-25 & & & & & & & & & & + & 4 & & + & & \\
\hline
\end{tabular}

+: Expressed; blank: not expressed.

completely sequenced, therefore the maize genome database used here is more precise and complete than what was previously available.

Although the maize genome is approximately 6-fold larger than rice $(2,300 \mathrm{Mb}: 389 \mathrm{Mb})$, the gene number is similar (3,2000:3,7000) and their genetic map organization is highly conserved. We found maize and rice have the same number of Hsfs [19]. This partially accounts for the support of Hsfs conservation in these two species during the evolutionary process. In the investigation of conserved Hsf domains, we observed two class A Hsfs (ZmHsf-02, ZmHsf-24) lacking the AHA motif, which is essential for class A Hsfs transcription activity. Previous study suggests [19] these proteins bind to other class A Hsfs forming hetero-oligomers to achieve their functions.

Phylogenetic analysis of Hsfs in maize, rice and Arabidopsis indicated that ZmHsfs are more closely allied with OsHsfs than AtHsfs, consistent with the evolutionary relationships among maize, rice and Arabidopsis i.e. two monocots in the Poaceae Subclass Commelinidae and one dicot in the Brassicaceae Subclass Dilleniidae. The fact that all three classes (A, B and C) identified in maize, rice and Arabidopsis genes implies that the Hsf genes originated prior to the divergence of monocots and dicots. Hsfs of rice and maize appear more close relationship between each other in subclass A1 than to Hsfs from Arabidopsis. Such observations suggest the expansion of these Hsf genes following divergence of monocots and dicots.

The phylogenetic analysis showed that AtHsf-04 (HsfA2 type) and AtHsf-08 (HsfC1 type) were not grouped into subclass $\mathrm{A} 2$ and class $\mathrm{C}$, respectively, and subclass A2 and class C were OsHsfs and ZmHsfs clusters. $\mathrm{ZmHsfs}$ and OsHsfs belong to the same clade, indicating that Hsfs of these subclasses expanded in a species-specific manner from common ancestral genes that were present prior to diversification of the monocot and dicot lineages. Phylogenetic data also proposed that subclass A2 and class C Hsfs were expanded in monocots but not in Arabidopsis. A single HsfA2 (AtHsf-04) is present in Arabidopsis. However, maize has four members and rice contains five in subclass A2. Class $\mathrm{C}$ consists of three maize and four rice members, while Arabidopsis has only one class $C$ type member (AtHsf-08). 

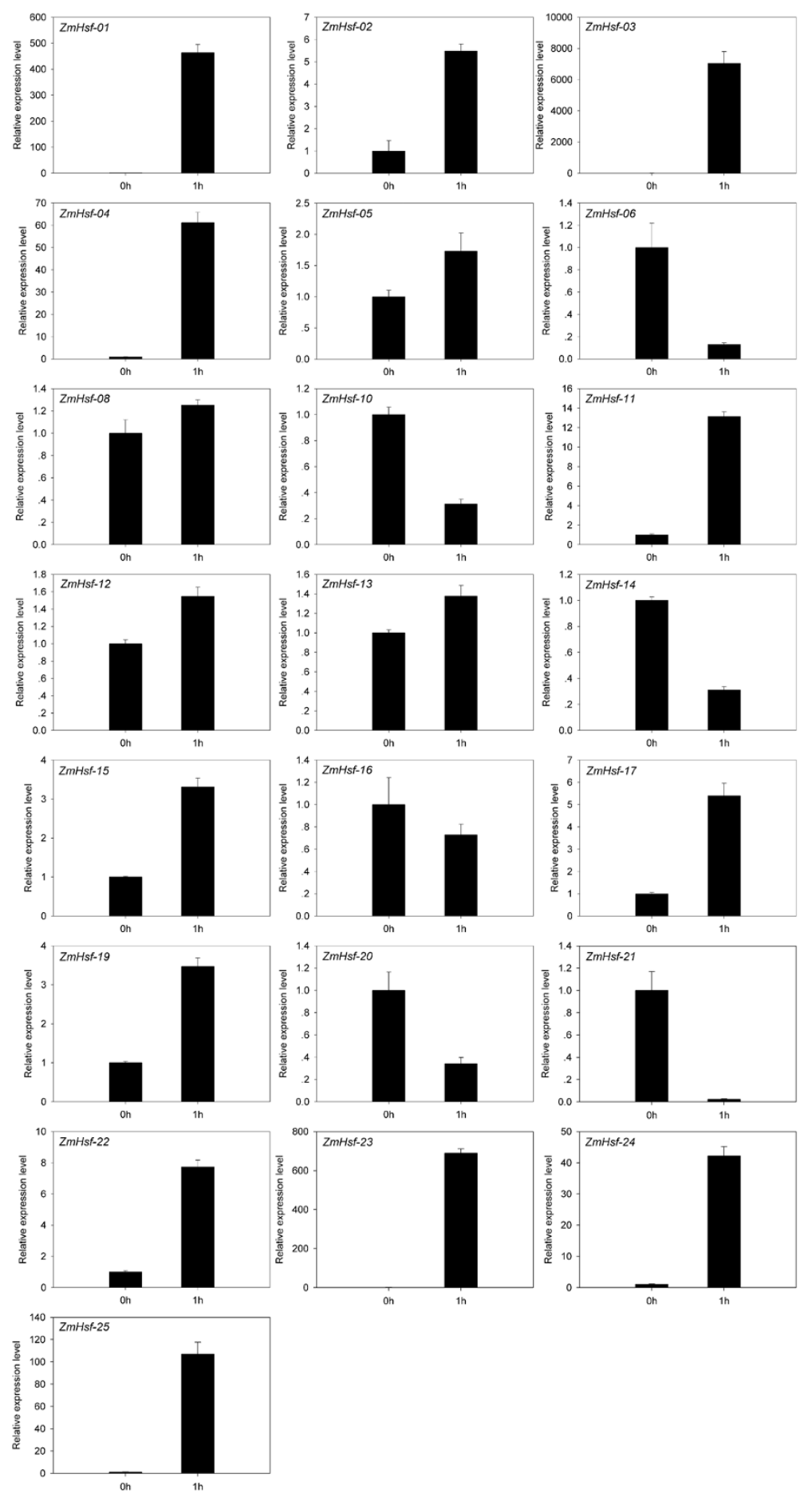

Figure 6 Relative gene expression of ZmHsfs analyzed by qRT-PCR responsed to heat stress treatment. qRT-PCR data was normalized using maize Actin 1 gene and are shown relative to $0 \mathrm{~h}$. $X$-axes are time course $(0 \mathrm{~h}$ and $1 \mathrm{~h})$ and $y$-axes are scales of relative expression level (error bars indicate SD). 
In addition, possible gene loss during the course of evolution was supported by phylogenetic reconstruction. Subclasses A7 and A8 exhibit interesting characteristics that monocots were not found in these two subclasses. Accordingly, this might indicates two dicot specific gene subclasses. Gene duplication events play a significant role in the amplification of gene family members in the genome [26,27]. Research has estimated the fraction of retained paralogs is $72 \%$ in maize, having occurred over the course of 11 million years of evolution [28]. The expansion mechanism of the maize Hsf gene family was analyzed to understand gene duplication events. Nine pairs of maize Hsf gene paralogs were identified. Among the paralogs, only one pair is involved in regional duplication in chromosome 1 , however, two members in each of the other eight pairs were arranged between chromosomes. This result suggested the maize Hsf gene family expansion originated in a high number of large segmental duplications. An increase in the number of gene regulators (i.e. transcriptional and developmental regulators and signal transducers) is an essential factor in the evolution of more complex systems in different species [29]. It is hard to achieve the expansions of these regulator gene classes only through single-gene duplications, which points to the importance of genome duplications in expanding the regulatory gene repertoire [30]. It was estimated that more than $90 \%$ increase in regulatory genes had been caused by genome duplications in the Arabidopsis lineage in the last approximately 150 million years [27]. Similarly, individual gene family expansion follows this rule. In plants, genome duplications have mainly contributed to expression of the Aux/IAA family of auxin response regulators [31]. Data from studies of the maize genome revealed that its genome has experienced two rounds of genome duplications, an ancient duplication prior to the maize-rice divergence and a recent event following triploidization [32]. The association of Hsf gene expansion in maize with these two rounds of maize genome duplication explains this observation and in addition sheds light on the evolutionary process of the maize Hsf gene family. Furthermore, segmental duplications occur more often in more slowly evolving gene families, e.g. MYB gene family [26]. Due to the major role of segmental duplications in the Hsf gene family evolution, the maize Hsf gene family might hold a slow evolutionary rate.

Several approaches were employed for maize Hsf gene expression analysis by EST database. ZmHsf genes exhibited distinct expression patterns in different tissues or organs. One explanation is that $Z m H s f$ genes have different expression patterns in various tissues and at multiple developmental stages. Expression profiles of 12 class A rice heat shock transcription factor genes have been resolved and the OsHsfA genes displayed tissue-specific expression under normal conditions [33]. AtHsfA9 was exclusively expressed during the late seed development stage and controlled by the seed-specific transcription factor abscisic acid-insensitive 3 (ABI3) [34]. Furthermore, the expression data revealed that the majority of duplicated $Z m H s f$ gene pairs exhibited diverse expression patterns between two members. It suggested that functional diversification of the surviving duplicated genes is a major feature of the long-term evolution [35].

Expression analysis of quantitative RT-PCR showed that maize Hsf genes exist different expression levels by heat stress. In this study, we have detected three HsfA2type ZmHsfs (ZmHsf-01, ZmHsf-04 and ZmHsf-17) with significantly higher expression, when subjected to heat stress. The result indicated that the $\mathrm{ZmHsfA2}$ subclass was closely related with maize heat shock response. Moreover, six genes were remarkably up-regulated under heat stress condition, i.e. $\mathrm{ZmHsf-01,} \mathrm{ZmHsf-03}$ and $Z m H s f-23$, and et al., which suggested specific roles for these genes in maize during heat stress. It is noteworthy that three ZmHsfs (ZmHsf-03, ZmHsf-11 and $\mathrm{ZmHsf-25)}$ assigned to class $\mathrm{B}$ appeared to be strongly induced by heat stress. The Hsfs belong to class B lack certain structural features of the class A activator Hsfs. Class B-Hsfs may serve as transcriptional repressors or coactivator cooperating with class A Hsfs. But the functional roles of these three Class B-Hsfs in maize will require further investigations. It is likely that the $H_{s f}$ genes remaining unaltered or down-regulated in expression may locate at downstream in the hierarchy of the events involved in heat shock response or are repressed by other members of the family [36]. In addition, if Hsp proteins accumulate enough, they may be involved in feedback regulation to repress $\mathrm{Hsfs}$ activity, such as Hsp70 proteins. In the nine duplicated gene pairs of maize, the significant divergence of expression levels between the two members of each gene pair implied that duplicated genes had various functions in the response to heat stress in the evolutionary history.

\section{Conclusions}

This survey presents a comprehensive overview of the Hsf gene family repertoire within the maize draft genome. Based on structural characteristics and a comparison of the phylogenetic relationships among maize, rice, and Arabidopsis, all $25 \mathrm{ZmHsfs}$ fell into three major classes (class A, B, C), and class A was organized into 10 subclasses. Further phylogenetic analysis revealed divergent expansion patterns of Hsf gene families in classes and subclasses. Our analyses suggest that whole genome and chromosomal segment duplications largely contributed to Hsf gene family expansion in maize. Our computational expression analyses suggest that many maize Hsf genes play functional developmental roles in multiple 
tissues. Furthermore, expression profiles by quantitative real-time PCR revealed that the majority of identified $Z m H s f s$ most likely are expressed in maize and these genes are induced by heat stress with differential induction levels in leaves. Overall, our study will serve to better understand the complexity of the maize Hsf gene family and guide future experimental work. Together with the availability of the complete maize genome sequence and the increasing ease of obtaining mutants and raising transgenics, our analysis should facilitate functional characterization studies to confirm maize Hsfs and deduce Hsfs gene roles in plant stress responses.

\section{Methods}

\section{Identification and physical locations of Hsf proteins in maize}

The maize genome sequence has been completed, and filtered protein and cds sequences have also become available [21]. Initially, due to the variation in Hsf sequences, nine protein sequences known as Hsf were used to search the Pfam (Protein family) database [37]. In this way, integrated and exact conserved Hsf-type DBD domain sequence based on the Hidden Markov Model (HMM) would be obtained. The nine query sequences were as follows: maize Hsf sequences [NCBI: ACG33027.1, ACG29285.1, ACG28818.1], rice Hsf sequences LOC_Os10g28340 (class A), LOC_Os04 g48030 (class B), and LOC_Os01g43590 (class C), and Arabidopsis Hsf sequences At4g17750 (class A), At4g36990 (class B), and At5g62020 (class C). Second, DNATOOLS software was used to build local databases from the maize complete genome nucleotide sequences and protein sequences. The Hsf domain numbered PF00447 obtained from the Pfam database was used as a standard sequence to isolate all possible homologs in maize by BLASTP searches $(P$-value $=0.001)$. This step was crucial to identify as many similar sequences as possible. Moreover, the starting locations of all candidate Hsf genes on each chromosome were acquired by TBLASTN $(P$-value $=0.001)$. Through this method, the physical locations of all candidate Hsf genes were confirmed and the redundant sequences with the same chromosome location were rejected from the Hsf candidate list. Furthermore, all candidate sequences that met the standards were analyzed in the Pfam database once more and were detected by the SMART program [38] for the purposes of eliminating any sequences not containing the Hsf-type DBD domain. Finally, the remaining sequences were checked by means of the SMART program to recognize coiled-coil structure, which is the core of the HR-A/B region. The sequences without coiled-coil structure were removed. A distinctive name for each of Hsfs identified in maize was given according to its position from the top to the bottom on the maize chromosomes 1 to 10. Finally, the chromosome location image of Hsf genes was generated by MapInspect software [39].

\section{Multiple sequence alignment and domain prediction}

Initially, ClustalX (version 1.83) [40] was performed to align amino acid sequences of Hsf proteins, which passed screening and were accepted. Subsequently, GeneDoc was used to manually edit the results. The domain analysis programs MARCOIL [41], PredictNLS [42] and NetNES 1.1 [43] were suitable for predicting coiled-coil domains, NLS and NES, respectively encoding Hsf genes. Additionally, the Hsf protein conserved motifs were defined by submitting their full-length amino acid sequences to MEME [44].

\section{Analysis of phylogenetic relationships and gene duplication}

Phylogenetic trees were constructed by the neighborjoining (NJ) method in MEGA (version 4.0) [45]. NJ analysis was performed with the Pairwise Deletion option and the Possion correction. For statistical reliability, bootstrap analysis was conducted with 1,000 replicates to assess statistical support for each node. S. cerevisiae Hsf1 (ScHsf1) was used as the outgroup.

Hsf gene duplication events were also investigated. MEGA (version 4.0) was used to align Hsf amino acid sequences by Clustal W and compute their evolutionary distances [46]. We defined a gene duplication according to the following criteria [46,47]: (1) the length of alignable sequence cover $>80 \%$ of the longer gene; and (2) the similarity of the aligned regions $>70 \%$.

\section{Digital expression analysis: EST expression profile}

The analysis of $\mathrm{ZmHsfs}$ expression profiles was accomplished by searching the maize dbEST database and finding expression information provided at the Web sites. Maize expression data was first obtained through blast searches against the maize dbEST database downloaded from NCBI by conducting the DNATOOLS Blast program. Searching parameters were as followings: maximum identity $>95 \%$, length $>200$ bp and Evalue $<10^{-}$

${ }^{10}$. In addition to the maize EST database, maize expression data was also extracted from the Maize Assembled Genomic Island (MAGI) [48] and the Plant Genomic Database (PlantGBD) [49] including EST, cDNA and PUTs (PlantGDB unique transcripts).

\section{Plant materials and stress treatment}

Maize (Zea mays L. inbred line B73) plants were grown in a greenhouse at $28 \pm 2{ }^{\circ} \mathrm{C}$ with a photoperiod of $14 \mathrm{~h}$ light and $10 \mathrm{~h}$ dark. For heat stress, uniform-sized seedlings were transferred to a growth chamber to $42 \pm 1^{\circ} \mathrm{C}$ when they developed three fully opened trifoliate leaves (approximately three weeks after sowing). The leaves of the seedlings were harvested after 0 and $1 \mathrm{~h}$ of heat 
stress treatment, frozen immediately in liquid nitrogen, and stored at $-80^{\circ} \mathrm{C}$ until RNA isolation.

\section{RNA isolation and quantitative real-time PCR (qRT-PCR) analyses}

To confirm the expression of representative of $\mathrm{ZmHsf}$ genes, total RNA was prepared using Trizol reagent (Invitrogen, USA), followed by DNase I treatment to remove any genomic DNA contamination. RNA concentration was determined by NanoDrop ND-1000 UV-Vis spectrophotometer (NanoDrop Technologies, Inc.) and the integrity of the RNA was assessed on a $1 \%(w / v)$ agarose gel. The first-strand cDNA was synthesized from $1 \mu \mathrm{g}$ of total RNA using QuantiTect Rev. Transcription Kit (Qiagen, Germany). Quantitative RT-PCR was carried out using an ABI PRISM 7300 real-time PCR system (Applied Biosystems, USA). Each reaction contains $10 \mu \mathrm{L}$ $2 \times$ SYBR Green Master Mix Reagent (Applied Biosystems, USA), $2.0 \mu \mathrm{L}$ cDNA sample, and $400 \mathrm{nM}$ of gene-specific primer in a final volume of $20 \mu \mathrm{L}$. Each pair of primers were designed by using Primer Express 3.0 software (Applied Biosystems, USA) targeting an amplicon size of 90-190 bp. The primers used are listed in the additional file 1 . The thermal cycle used was as follows: $50^{\circ} \mathrm{C}$ for 2 min, $95^{\circ} \mathrm{C}$ for $10 \mathrm{~min}, 40$ cycles of $95^{\circ} \mathrm{C}$ for $15 \mathrm{~s}$, and $60^{\circ}$ $\mathrm{C}$ for $1 \mathrm{~min}$. The specificity of the reactions was verified by melting curve analysis. The relative mRNA level for each gene was calculated as $\Delta \Delta C_{\mathrm{T}}$ values in comparison to unstressed seedlings (Applied Biosystems, USA). Maize Actin 1 gene was used as internal control for normalization. At least three replicates of each cDNA sample were performed for quantitative RT-PCR analysis.

\section{Additional material}

Additional file 1: Primers used in quantitative real-time PCR. Excel document contains two tables listing primer sequences used for quantitative real-time PCR to validate expression patterns of $\mathrm{ZmHsf}$ genes.

\section{List of Abbreviations}

AHA: activator motif; CTAD: C-terminal activation domain; DBD: DNA-binding domain; HS: heat shock; HSEs: heat shock elements; Hsfs: heat shock transcription factors; NES: nuclear export signal; NLS: nuclear localization signal; qRT-PCR: quantitative real-time PCR.

\section{Acknowledgements}

This work was supported by grants from the Key Projects in the National Science \& Technology Pillar Program (No. 2009BADA6B00), the Genetically Modified Organisms Breeding Major Projects (Grant No.2008ZX08010-002) and the Anhui Natural Science Foundation of China (Grant No.10675002). We are grateful to Dr. X. Zhang for her assistance in proofreading and editing this manuscript. We are also grateful to $Y$. Zhao for his help in conduction of quantitative real-time PCR analysis.

\section{Authors' contributions}

These studies were designed by $Y X L, H Y J$ and BJC. YXL carried out all the experimental analyses and prepared all figures and tables. YXL and HYJ analyzed the data and drafted the manuscript. ZXC and XLT contributed to revisions of the manuscript. BJC and SWZ assisted in explaining the results and revised the final version of the manuscript. All authors have read and approved the final manuscript.

Received: 14 August 2010 Accepted: 27 January 2011

Published: 27 January 2011

\section{References}

1. Hartl FU, Hayer-Hartl M: Molecular chaperones in the cytosol: from nascent chain to folded protein. Science 2002, 295:1852-1858.

2. Morimoto Rl, Tissieres A, Georgopoulos C: Progress and perspectives on the biology of heat shock proteins and molecular chaparones. In The biology of heat shock proteins and molecular chaperones. Edited by: Morimoto Rl, Tissieres A, Georgopoulos C. Cold Spring Harbor: Cold Spring Harbor Laboratory Press; 1994:1-31.

3. Morimoto Rl: Dynamic remodeling of transcription complexes by molecular chaperones. Cell 2002, 110:281.

4. Nover L, Bharti K, Döring P, Mishra SK, Ganguli A, Scharf KD: Arabidopsis and the heat stress transcription factor world: how many heat stress transcription factors do we need? Cell Stress Chaperones 2001, 6:177-189.

5. Bienz M, Pelham HR: Mechanisms of heat-shock gene activation in higher eukaryotes. Adv Genet 1987, 24:31-72.

6. Xiao H, Lis JT: Germline transformation used to define key features of heat-shock response elements. Science 1988, 239:1139-1142.

7. Xiao H, Perisic O, Lis JT: Cooperative binding of Drosophila heat shock factor to arrays of a conserved 5 bp unit. Cell 1991, 64:585-593.

8. Scharf KD, Rose S, Zott W, Schoffl F, Nover L: Three tomato genes code for heat stress transcription factors with a region of remarkable homology to the DNA-binding domain of the yeast HSF. EMBO J 1990, 9:4495-4501.

9. Hübel A, Schöffl F: Arabidopsis heat shock factor: isolation and characterization of the gene and the recombinant protein. Plant Mol Biol 1994, 26:353-362.

10. Czarnecka-Verner E, Yuan CX, Fox PC, Gurley WB: Isolation and characterization of six heat shock transcription factor CDNA clones from soybean. Plant Mol Biol 1995, 29:37-51.

11. Aranda MA, Escaler $M$, Thomas $C L$, Maule AJ: $A$ heat stress transcription factor in pea is differentially controlled by heat and virus replication. Plant J 1999, 20:153-161.

12. Baniwal SK, Bharti K, Chan KY, Fauth M, Ganguli A, Kotak S, Mishra SK, Nover L, Port M, Scharf KD, Tripp J, Weber C, Zielinski D, Döring P: Heat stress response in plants: a complex game with chaperones and more than twenty heat stress transcription factors. J Biosci 2004, 29:471-487.

13. Kotak S, Port M, Ganguli A, Bicker F, Döring P: Characterization of Cterminal domains of Arabidopsis heat stress transcription factors (Hsfs) and identification of a new signature combination of plant class A Hsfs with AHA and NES motifs essential for activator function and intracellular localization. Plant J 2004, 39:98-112.

14. Harrison CJ, Bohm AA, Nelson HC: Crystal structure of the DNA binding domain of the heat shock transcription factor. Science 1994, 263:224-227.

15. Peteranderl R, Rabenstein M, Shin YK, Liu CW, Wemmer DE, King DS, Nelson HC: Biochemical and biophysical characterization of the trimerization domain from the heat shock transcription factor. Biochemistry 1999, 38:3559-3569.

16. Lyck R, Harmening U, Hohfeld I, Treuter E, Scharf KD, Nover L: Intracellular distribution and identification of the nuclear localization signals of two plant heat-stress transcription factors. Planta 1997, 202:117-125.

17. Heerklotz D, Döring P, Bonzelius F, Winkelhaus S, Nover L: The balance of nuclear import and export determines the intracellular distribution and function of tomato heat stress transcription factor HsfA2. Mol Cell Biol 2001, 21:1759-1768.

18. Döring P, Treuter E, Kistner C, Lyck R, Chen A, Nover L: The role of AHA motifs in the activator function of tomato heat stress transcription factors HsfA1 and HsfA2. Plant Cell 2000, 12:265-278.

19. Guo J, Wu J, Ji Q, Wang C, Luo L, Yuan Y, Wang Y, Wang J: Genome-wide analysis of heat shock transcription factor families in rice and Arabidopsis. J Genet Genomics 2008, 35:105-118.

20. Gagliardi D, Breton C, Chaboud A, Vergne P, Dumas C: Expression of heat shock factor and heat shock protein 70 genes during maize pollen development. Plant Mol Biol 1995, 29:841-856 
21. Schnable PS, Ware D, Fulton RS, Stein JC, Wei F, Pasternak S, Liang C, Zhang J, Fulton L, Graves TA, Minx P, Reily AD, Courtney L, Kruchowski SS, Tomlinson C, Strong C, Delehaunty K, Fronick C, Courtney B, Rock SM, Belter E, Du F, Kim K, Abbott RM, Cotton M, Levy A, Marchetto P, Ochoa K, Jackson SM, Gillam B, Chen W, Yan L, Higginbotham J, Cardenas M, Waligorski J, Applebaum E, Phelps L, Falcone J, Kanchi K, Thane T, Scimone A, Thane N, Henke J, Wang T, Ruppert J, Shah N, Rotter K, Hodges J, Ingenthron E, Cordes M, Kohlberg S, Sgro J, Delgado B, Mead K, Chinwalla A, Leonard S, Crouse K, Collura K, Kudrna D, Currie J, He R, Angelova A, Rajasekar S, Mueller T, Lomeli R, Scara G, Ko A, Delaney K, Wissotski M, Lopez G, Campos D, Braidotti M, Ashley E, Golser W, Kim HR, Lee S, Lin J, Dujmic Z, Kim W, Talag J, Zuccolo A, Fan C, Sebastian A, Kramer M, Spiegel L, Nascimento L, Zutavern T, Miller B, Ambroise C, Muller S, Spooner W, Narechania A, Ren L, Wei S, Kumari S, Faga B, Levy MJ, McMahan L, Buren PV, Vaughn MW, Ying K, Yeh CT, Emrich SJ, Jia Y, Kalyanaraman A, Hsia AP, Barbazuk WB, Baucom RS, Brutnell TP, Carpita NC, Chaparro C, Chia JM, Deragon JM, Estill JC, Fu Y, Jeddeloh JA, Han Y, Lee H, Li P, Lisch DR, Liu S, Liu Z, Nagel DH, McCann MC, SanMiguel P, Myers AM, Nettleton D, Nguyen J, Penning BW, Ponnala L, Schneider KL, Schwartz DC, Sharma A, Soderlund C, Springer NM, Sun Q, Wang H, Waterman M, Westerman R, Wolfgruber TK, Yang L, Yu Y, Zhang L, Zhou S, Zhu Q, Bennetzen JL, Dawe RK, Jiang J, Jiang N, Presting GG, Wessler SR, Aluru S, Martienssen RA, Clifton SW, McCombie WR, Wing RA, Wilson RK: The B73 maize genome: complexity, diversity and dynamics. Science 2009, 326:1112-1115.

22. Scharf KD, Heider H, Hohfeld I, Lyck R, Schmidt E, Nover L: The tomato Hsf system: HsfA2 needs interaction with HsfA1 for efficient nuclear import and may be localized in cytoplasmic heat stress granules. Mol Cell Biol 1998, 18:2240-2251.

23. TIGR: [http://www.tigr.org].

24. TAIR: [http://www.arabidopsis.org/].

25. Fu S, Rogowsky P, Nover L, Scanlon MJ: The maize heat shock factorbinding protein paralogs EMP2 and HSBP2 interact non-redundantly with specific heat shock factors. Planta 2006, 224:42-52.

26. Cannon SB, Mitra A, Baumgarten A, Young ND, May G: The roles of segmental and tandem gene duplication in the evolution of large gene families in Arabidopsis thaliana. BMC Plant Biology 2004, 4:53-62.

27. Maere S, de Bodt S, Raes J, Casneuf T, Montagu MV, Kuiper M, de Peer YV: Modeling gene and genome duplications in eukaryotes. Proc Natl Acad Sci USA 2005, 102:5454-5459.

28. Ahn S, Tanksley SD: Comparative linkage maps of the rice and maize genomes. Proc Natl Acad Sci USA 1993, 90:7980-7984.

29. Sole RV, Fernandez P, Kauffman SA: Adaptive walks in a gene network model of morphogenesis: insights into the Cambrian explosion. Int J Dev Biol 2003, 47:685-693.

30. Van de Peer $Y$, Maere S, Meyer A: The evolutionary significance of ancient genome duplications. Nature Reviews Genetics 2009, 10:725-732.

31. Remington DL, Vision TJ, Guilfoyle TJ, Reed JW: Contrasting modes of diversification in the Aux/IAA and ARF gene families. Plant Physiol 2004, 135:1738-1752.

32. Wei F, Coe E, Nelson W, Bharti AK, Engler F, Butler E, Kim H, Goicoechea JL, Chen M, Lee S, Fuks G, Sanchez-Villeda H, Schroeder S, Fang Z, McMullen M, Davis G, Bowers JE, Paterson AH, Schaeffer M, Gardiner J, Cone K, Messing J, Soderlund C, Wing RA: Physical and genetic structure of the maize genome reflects its complex evolutionary history. PLoS Genetics 2007, 3:1254-1263.

33. Liu AL, Zou J, Zhang XW, Zhou XY, Wang WF, Xiong XY, Chen LY, Chen XB: Expression Profiles of Class A Rice Heat Shock Transcription Factor Genes Under Abiotic Stresses. J Plant Biol 2010, 53:142-149.

34. Kotak S, Vierling E, Bäumlein H, von Koskull-Döring P: A nove transcriptional cascade regulating expression of heat stress proteins during seed development of Arabidopsis. Plant Cell 2007, 19:182-195.

35. Blanc $\mathrm{G}$, Wolfe KH: Functional divergence of duplicated genes formed by polyploidy during Arabidopsis evolution. Plant Cell 2004, 16:1679-1691.

36. Mittal D, Chakrabarti S, Sarkar A, Singh A, Grover A: Heat shock factor gene family in rice: genomic organization and transcript expression profiling in response to high temperature, low temperature and oxidative stresses. Plant Physiol Biochem 2009, 47:785-795.

37. Finn RD, Mistry J, Tate J, Coggill P, Heger A, Pollington JE, Gavin OL, Gunasekaran P, Ceric G, Forslund K, Holm L, Sonnhammer ELL, Eddy SR,
Bateman A: The Pfam protein families database. Nucleic Acids Res 2010, 38 Database: 211-222 [http://pfam.sanger.ac.uk/search/sequence].

38. Letunic I, Doerks T, Bork P: SMART 6: recent updates and new developments. Nucleic Acids Res 2009, , 37 Database: 229-232.

39. Maplnspect software. [http://www.plantbreeding.wur.n//UK software_mapinspect.html].

40. Thompson JD, Gibson TJ, Plewniak F, Jeanmougin F, Higgins DG: The ClustalX windows interface: flexible strategies for multiple sequence alignment aided by quality analysis tools. Nucleic Acids Res 1997, 24:4876-4882.

41. Delorenzi M, Speed T: An HMM model for coiled-coil domains and a comparison with PSSM-based predictions. Bioinformatics 2002, 18:617-625.

42. Cokol M, Nair R, Rost B: Finding nuclear localization signals. EMBO Rep 2000, 1:411-415.

43. la Cour T, Kiemer L, Molgaard A, Gupta R, Skriver K, Brunak S: Analysis and prediction of leucine-rich nuclear export signals. Protein Eng Des Sel 2004, 17:527-536.

44. Bailey TL, Elkan C: The value of prior knowledge in discovering motifs with MEME. Proc Int Conf Intell Syst Mol Biol 2005, 3:21-29.

45. Tamura K, Dudley J, Nei M, Kumar S: MEGA4: Molecular Evolutionary Genetics Analysis (MEGA) software version 4.0. Molecular Biology and Evolution 2007, 24:1596-1599.

46. Yang S, Zhang X, Yue JX, Tian D, Chen JQ: Recent duplications dominate NBS-encoding gene expansion in two woody species. Molecular Genetics and Genomics 2008, 280:187-198.

47. Gu Z, Cavalcanti A, Chen FC, Bouman P, Li WH: Extent of gene duplication in the genomes of Drosophila, nematode, and yeast. Mol Biol Evol 2002, 19:256-262.

48. MAGI. [http://magi.plantgenomics.iastate.edu/]

49. Plant GBD. [http://www.plantgdb.org/].

doi:10.1186/1471-2164-12-76

Cite this article as: Lin et al:: Genome-wide identification, classification and analysis of heat shock transcription factor family in maize. BMC Genomics 2011 12:76.

\section{Submit your next manuscript to BioMed Central and take full advantage of:}

- Convenient online submission

- Thorough peer review

- No space constraints or color figure charges

- Immediate publication on acceptance

- Inclusion in PubMed, CAS, Scopus and Google Scholar

- Research which is freely available for redistribution 